\title{
Battles on radiation safety
}

SIR-Your recent leading article ("Hard battles on radiation safety" Nature 329, $185 ; 1987)$ is a generally accurate and evenhanded statement, but it does not seem adequately to stress the magnitude or the relative importance of the problems involved.

As you say, the "dose" limits (for general populations) recommended by the International Committee on Radiological Protection (ICRP) amount to less than the doses received from background (radiation). As background is subject to substantial geographic variation, one might assume that comparisons of the incidence of deleterious effects (especially cancer mortality) in regions where the background levels differ could permit an estimate of the risks posed by ICRP recommendations. A number of such studies (often involving vast populations) have been made and more often than not they have indicated that the cancer mortality is less where the background level is higher. The value of the results of any of these projects is, however, dubious, as evidenced by quite substantial variations in cancer mortality among regions having similar background levels. This rather unsurprising finding would seem to doom any epidemiological evaluation of the risks implied by ICRP recommendations.

Further analysis of the data from Hiroshima and Nagasaki, and possibly also from Chernobyl, may improve our imprecise estimates on the induction of cancer and maybe even of genetic damage when caused by substantial fractions of a sievert. I do not believe that anyone with knowledge of the epidemiological difficulties involved expects any meaningful evidence at 1 or even $10 \mathrm{mSv}$.

Such data can therefore be used only in conjunction with extrapolations. While casting some doubt on the notion of proportionality, you state that the existence of a threshold for cancer induction is "unlikely on theoretical grounds". The theory involved is quite naive, as shown by the well-established fact that the natural incidence of a few animal tumours is reduced by modest doses of radiation that cause excess incidence of other tumours. But in experimental radiobiology, too, our knowledge of what happens at a few $\mathrm{mSv}$ is generally sparse.

In view of these uncertainties, it cannot be said to be unreasonable for ICRP to employ linear extrapolations in attempting to quantify radiation risks. It has based such estimates on the best available data, and it will no doubt revise them, if warranted, when seemingly better data become available. What should be criticized is its hesitancy to state clearly that the risk figures are nominal rather than actual.
The significance of radiation risks is, however, largely a polemical issue. Most people (and probably many of the signatories of the petition to the ICRP) would not hold the hazards of background radiation worth considering when deciding whether to move from Florida to Colorado (or the other way). It is difficult to discount the impression that the petitioners were motivated by politics or ideology rather than by genuine concern over radiation safety.

HaRALD H. Rossi

Department of Radiation Oncology,

College of Physicians \& Surgeons

of Columbia University,

PO Box 21

Irvington,

New York 10533, USA

\section{Emergency plans}

SIR-The analysis in "US nuclear elephants stay white" (Nature 328, 561; 1987 ) is seriously flawed by the author's lack of understanding of how emergency planning is accomplished under the federal system of the United States. Under that system, no agency in the federal government, including the Nuclear Regulatory Commission (NRC), is responsible for developing an emergency plan for a nuclear reactor. Rather, the development of such a plan is the responsibility of the state and/or local governments in whose jurisdiction the particular reactor is located.

Thus the acceptability of an emergency plan is not simply a question of whether the local authorities think it makes sense: if those local authorities decide not to participate in that plan, there is no workable plan. Even the NRC acknowledges this in its assumption that a utility plan is a workable substitute only because, in the event of an emergency, state and local governments will be compelled to participate despite previous disclaimers of any intention to do so.

These realities, and the confusion over evacuation authority after the accident at Three Mile Island, left the NRC no practical choice in 1980 but to institutionalize the critical role of local interests in emergency planning. The issue, therefore, is not whether the NRC made a mistake in 1980 by giving local interests such a powerful voice in national energy interests. Rather, it is why local interests at only two of over sixty sites have chosen not to participate in emergency planning.

One answer, which seems to have been dismissed too cavalierly, is economics. The traditional rate basing of Shoreham would further exaggerate Long Island's unenviable position of already having one of the nation's highest electric rates. It is this local economic reality that seems to have led local Long Island politicians to seize on emergency planning as a way to stop the licensing of Shoreham until a workable rate treatment could be achieved. But now, having mounted that proverbial tiger's back, no one can dismount gracefully. That will happen only when the affected interests are candid about their concerns.

By the way, Peach Bottom is in Pennsylvania.

5825 S Blackstone,

Sheldon L. TRubatch

Chicago, Illinois 60637, USA

\section{Staying on}

SIR--In response to the letter of J.G. Wilson (Nature 328, 288; 1987), the fundamental absurdity of racial discrimination is that it is based on something beyond the control of the person(s) at which it is aimed, namely being born into one race rather than another. Wilson is guilty of exactly the same offence. He condemns all (white) South African scientists (who "choose to enjoy the advantages of living comfortably in South Africa, at the expense of the black population" - my italics) to be "denied the benefits of attendance at international conferences and so on".

To condemn South African scientists as racists, to be unaware that much of what politicians do is quite unacceptable but beyond the control of scientists and to hold it against us that we were born white and in South Africa is naive and just another step in a whirlpool of racism. I find it sad that scientists, who often claim to be the most rational of academics, have to resort to racism in their attempts to fight the very same.

Does Wilson recommend that South African scientists all leave the country, become politicians or revolutionaries? Many scientists have already left this country but many of us are staying. We are staying not because we see ourselves in privileged positions or because we want to suppress black people, but because by continuing to do research we feel we are working towards a better life for all in this country, no matter who is in government. We are not unthinking dinosaurs but have evaluated the very real uncertainty of our future and have chosen to stay because we are Africans, and do not wish to be "resettled" anywhere else on this planet as was arrogantly suggested by W.D. Stein (Nature 328, 374; 1987). We are able to accept the responsibility of our situation, even though many of us have not brought it about.

George Dennili

Plant Protection Research Institute,

Private Bag X5017,

Stellenbosch 7600 ,

South Africa 